\title{
DOUBLE FEMORAL OSTEOTOMY FOR THE TREATMENT OF SEVERE SEQUELAE OF THE IMMATURE HIP
}

\author{
DUPLA OSTEOTOMIA DO FÊMUR PARA O TRATAMENTO \\ DE GRAVES SEQUELAS NO QUADRIL IMATURO
}

\author{
Mariana Demétrio de Sousa Pontes ${ }^{1}$ (i), Paulo Henrique Bortolin ${ }^{1}$ [i], José Batista Volpon ${ }^{1}$ (i) \\ 1. Universidade de São Paulo, Hospital das Clínicas, Ribeirão Preto Medical School, Department of Orthopedics and Anesthesiology, Ribeirão Preto, SP, Brazil.
}

\section{ABSTRACT}

Objective: To evaluate the results of double femoral osteotomy for the treatment of severe sequelae of the hip. Methods: Immature patients with anatomical loss of the hip were treated with pelvic support osteotomy in the distal femur to correct lower limb shortening, they were evaluated clinically and radiographically. Results: Eleven cases (eleven hips) were assessed with verage follow-up of three years. The mean age of the patients was 14.7 years. Seven patients had sequela of infectious arthritis; three had sequela of developmental dysplasia of the hip and one patient had a sequela of slipped capital femoral epiphysis. Preoperatively, the gluteus medius was insufficient in all patients, and it became negative in ten of them. The average of lower limb shortening was $5 \mathrm{~cm}(2.5$ to $7 \mathrm{~cm})$ and reduced shortening was $1.9 \mathrm{~cm}(0$ to $4 \mathrm{~cm}$ ). According to Paley Classification, $72.7 \%$ of complications were considered problems, $90.9 \%$ were considered obstacles and $27.2 \%$ complications, among which the limitation of the knee flexion was the most frequent. Conclusion: The technique yielded good results, considering the severity of the sequela and the absence of a better therapeutic option. No important sequela was associated with the treatment. Level of Evidence IV, Case series.

Keywords: Hip Joint. Hip Dislocation. Osteotomy. Arthritis, Infectious.

\section{RESUMO}

Objetivo: Avaliar os resultados do tratamento de graves sequelas do quadril pela dupla osteotomia do fêmur. Métodos: Pacientes imaturos, com perda da articulação do quadril, foram tratados com osteotomia de apoio pélvico associada à osteotomia na região distal do fêmur para correção do eixo do membro inferior e do encurtamento, foram avaliados clínica e radiograficamente. Resultados: Onze casos (onze quadris) foram avaliados, com seguimento médio de três anos. A média de idade no tratamento foi de 14,7 anos. Sete indivíduos tinham sequela de artrite séptica, três de displasia do desenvolvimento do quadril e um de escorregamento epifisário proximal do fêmur. Pré-operatoriamente, a marcha por insuficiência do glúteo médio esteve presente em todos os sujeitos e se tornou negativa em dez deles. O encurtamento médio inicial do membro afetado foi de $5 \mathrm{~cm}(2,5 \mathrm{a} 7 \mathrm{~cm})$ e o reduzido teve média de $1,9 \mathrm{~cm}$ (0 a 4 cm). Segundo classificação de Paley, 72,7\% apresentaram intercorrências consideradas problemas, 90,9\% obstáculos e 27,2\% complicações, entre as quais a limitação da amplitude de movimento do joelho foi a mais frequente. Conclusão: A técnica produziu bons resultados em face da gravidade da sequela e da falta de outra opção terapêutica melhor. Não houve sequela importante associada ao tratamento. Nível de Evidência IV, Série de casos.

Descritores: Articulação do Quadril. Luxação do Quadril. Osteotomia. Artrite Infecciosa.

Citation: Pontes MDS, Bortolin PH, Volpon JB. Double femoral osteotomy for the treatment of severe sequelae of the immature hip. ilizarov technique. Acta Ortop Bras. [online]. 2020;28(6):287-290. Available from URL: http://www.scielo.br/aob.

\section{INTRODUCTION}

Hip function is very compromised by severe situations such as joint dislocations, or major joint destruction, as occurs in long-dated sequelae of infectious arthritis. There is no adequate treatment for these conditions, especially in young people, in whom the possibility of a total hip arthroplasty is discarded. The same occurs for arthrodesis since this is a radical procedure that causes great limitations and is currently little practiced. ${ }^{1}$
Individuals with these sequelae present severe abductor insufficiency, severe shortening and vicious position of the lower limb. The outcome of this combination is a serious alteration in posture, Trendelenburg gait-due to insufficiency of the gluteus medius-, movement restriction, claudication and difficult-to-treat pain. In 1919, the first attempt to alleviate this condition occurred when Lorenz described a pelvic support osteotomy, ${ }^{2}$ which was performed in the femur and caused a large valgus-related angle whose vertex

All authors declare no potential conflict of interest related to this article.

The study was conducted at Universidade de São Paulo, Hospital das Clínicas, Ribeirão Preto Medical School, Pediatric Orthopedics Sector. Correspondence: José Batista Volpon. Rua São José, 655, Ribeirão Preto, SP, Brazil, 14010160. hc.ortopedia@gmail.com 
was introduced into the acetabulum, thus creating a support to the pelvis and reducing the insufficiency of the gluteus medius. This technique received several variations, but Schanz contributed the most, by standardizing the level of osteotomy, transferring the support from within the acetabulum to the pelvis. ${ }^{2}$ Although the Trendelenburg gait-due to abductor insufficiency-was improved, a great limitation persisted because of the shortening and positioning in limb abduction caused by surgery, which created other limitations, even in the opposite knee. This scenario changed in 1980, when llizarov added to the original technique a distal osteotomy in the femur to realign the lower limb and lengthen it at the same time..$^{3,4}$ Currently, this technique is the most appropriate for treating loss of hip function in young people. ${ }^{5}$ Nevertheless, because it is a complex technique, performed in specialized centers and requires familiarity with the external fixation apparatus, there are few international reports about it and, as far as we know, none from Brazil.

This report aims to evaluate our results with the technique of double femoral osteotomy by the llizarov's technique to treat the sequelae of destroyed hip in young patients.

\section{MATERIALS AND METHODS}

This study is an individualized, observational and descriptive series of cases carried out in a tertiary university hospital of the SUS network, approved by the Research Ethics Committee of the Institution (No. 913, 2018) and registered in Plataforma Brasil (No. 2,501,360), according to the 1995 Declaration of Helsinki. All study participants signed an informed consent form.

The sample was composed of individuals of both genders, older than 11 years at the time of treatment, with severe sequelae in one hip, who were submitted to Schanz's pelvic support osteotomy associated with distal osteotomy of the femur, to align the lower limb and correct the shortening (Ilizarov technique). The stabilization of the two osteotomies was carried out with the llizarov external apparatus. Cases treated from 2007 to 2017 were included. Individuals diagnosed with cerebral palsy or other neuromuscular conditions, or with impairment of both hips were excluded.

Data collection was performed in a single phase by reviewing medical records, with the following study variables: gender, age, basic etiological diagnosis, type of hip destruction, test to detect weakness in the hip abductor (Trendelenburg), difference in length of the lower limbs on panoramic radiography, difficulties found during treatment and gait clinical characteristics.

The events that occurred in the different stages of treatment were classified, according to Paley ${ }^{6}$ as problems, obstacles, and complications. Problems are the difficulties that do not require surgical intervention to be solved. Obstacles are difficulties solved with new surgical interventions. Complications are defined as injuries during surgery, or difficulties during lengthening that have not been solved and compromise the result.

\section{Surgical technique}

For planning the osteotomies, an anteroposterior radiograph of the basin, in supine position, and maximum hip adduction was taken (Figure 1A). In this radiograph, a line tangent to the sciatic ischial tuberosity was drawn until crossing the affected femur, highlighting the site for the surgery (Figure 1B). A second frontal radiograph of the basin was taken with the individual standing and supported only by the affected limb. Based on the horizontal line of the pelvis, tangent to the iliac crests, a perpendicular line was drawn towards the femur. Then the angle formed between this line and the longitudinal axis of the femur was measured and $15^{\circ}$ were added for hypercorrection (Figure 1C). This is the valgus-related angle for the proper pelvic support. In the frontal plane, if a flexural contracture occurs, it should be corrected, increasing $5^{\circ} .7$ Also, if a rotational misalignment occurs, it should be corrected at this time. The second osteotomy is carried out distally in the femur for limb lengthening and frontal axis correction and, before the surgical procedure, it should be simulated with cut-out on tracing paper. The osteotomy level is located at the intersection site of the proximal mechanical axis (perpendicular to the horizontal line of the pelvis, passing through the apex of the proximal osteotomy) and crossing the longitudinal axis of the femur (Figure 1D). The final mechanical axis, after angular corrections, must be perpendicular to the horizontal line of the pelvis (Figure 1E). ${ }^{7}$
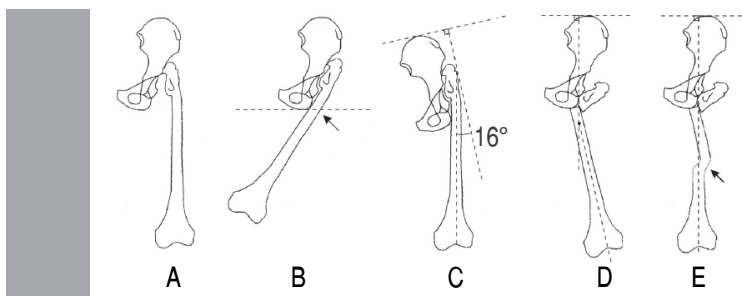

Figure 1. Surgical planning of the technical procedure.

A: example of destruction of the left femoral head, with limb shortening and pelvic-femoral instability; $\mathrm{B}$ : a line tangent to sciatic tuberosities is drawn on the radiograph with maximum hip adduction. This will be the valgus-related angle for the pelvic support; $\mathrm{D}$ : then a simulation of the proximal osteotomy is carried out, with cut-outs on tracing paper. The second osteotomy is performed distally, and it determines the positioning of the external fixation apparatus hinge that is determined by the andit determines the positioning of the external fixation apparatus hinge that is determined by the axis of the fixation apparatus (arrow). The final mechanical axis after lengthening and sweeping for axis correction must be perpendicular to the horizontal line of the pelvis.

In the surgery, the angulation of the proximal osteotomy was sharply carried out, according to the planned angle. Distal percutaneous osteotomy was carried out at the site previously estimated after the external fixation apparatus was installed. In this osteotomy, both angulation and lengthening were performed progressively, according to the llizarov technique.

\section{RESULTS}

Out of the eleven subjects studied, six (54.6\%) were male, aged between 11 and 20 years old at the time of surgery, 14.7 years as means age and a median of 15 years. Seven patients presented sequelae of septic arthritis of the hip, three presented sequelae of developmental dysplasia of the hip, and one had sequelae of slipped capital femoral epiphysis. Furthermore, 10 (90.9\%) patients presented a dislocated hip before the surgery and, in nine of them (81.8\%) the femoral head disappeared on the radiograph. In two cases (18.2\%) the head of the femur had been surgically resected. The mean follow-up time was three years.

Figure 2 shows a case,with radiographs before, during and at the end of the treatment.

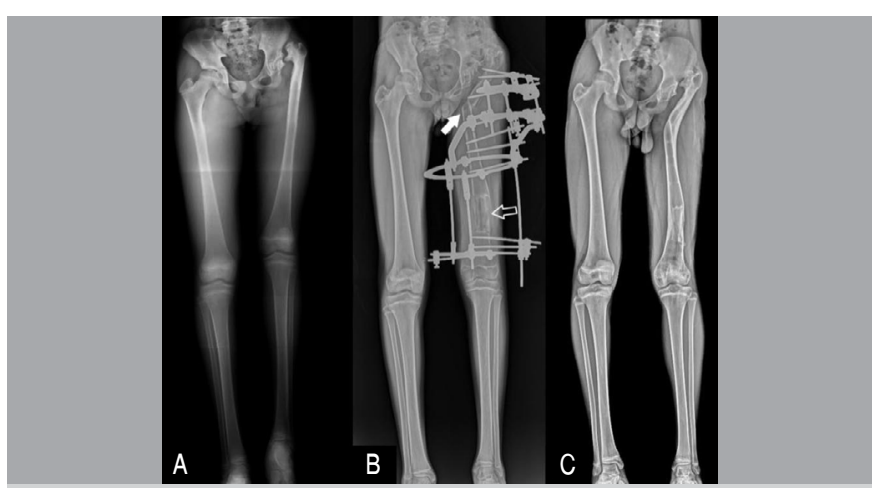

Figure 2. Sequence of radiographs illustrating the main technical steps. A: panoramic radiographs of the lower limbs of a 13-year-old patient with childhood infectious arthritis. Preoperatively, the hip is dislocated, in adduction and great shortening of the left lower limb; $\mathrm{B}$ : aspect after pelvic support osteotomy and during the axis correction and limb lengthening. The full arrow shows the proximal osteotomy and the empty arrow indicates the site of distal osteotomy, as well as the segment in lengthening; C: End of treatment. There are $3 \mathrm{~cm}$ of shortening left that still cause pelvic inclination. A new lengthening can be planned in the distal region of the femur. 
In the preoperative assessment, we observed that all patients could walk, but with an equinus foot deformity, limp or contralateral knee flexion as a compensation. The limp was caused by hip abductor insufficiency and limb shortening. The Trendelenburg test presented positive results in all cases and 10 of them $(90.9 \%)$ were normalized after treatment. The discrepancy in the length of the lower limbs before treatment ranged between 2.5 and $7 \mathrm{~cm}$, with a mean of $5 \mathrm{~cm}$ and, at the end, it was reduced to a mean of $1.9 \mathrm{~cm}(0$ to $4 \mathrm{~cm})$. According to the Paley classification, ${ }^{6}$ eight individuals presented problems (72.7\%), 10 presented obstacles (90.9\%) and three presented complications during limb lengthening (27.2\%). The issues were: stiffness on the knee joint in one individual (9\%) and infection in the external fixation pins of the apparatus of seven individuals (63.6\%). These cases were treated with physical therapy and antibiotics, respectively. The obstacles found consisted of restricted range of motion of the knee, which was resolved by manipulation under anesthesia, in 10 cases (90.9\%). There was one case of early consolidation of the regenerated bone, one case of recurve deformity of regenerated bone and two cases of late fracture in the proximal osteotomy (18.1\%). The bone fractures were surgically resolved with open reduction and internal fixation with a molded plate according to the previous valgus-related angle osteotomy, redoing the pelvic support (Figure 3). Early consolidation was solved with osteotomy of the regenerated bone. A total of two cases $(18.1 \%)$ were considered a complication, with limited range of motion on the knee, and they were not solved by manipulation under anesthesia and were treated with quadricepsplasty and recovery of part of the functional range of motion. No patient in this study presented consolidation delay, pseudoarthrosis, deep infection or neurovascular injury.

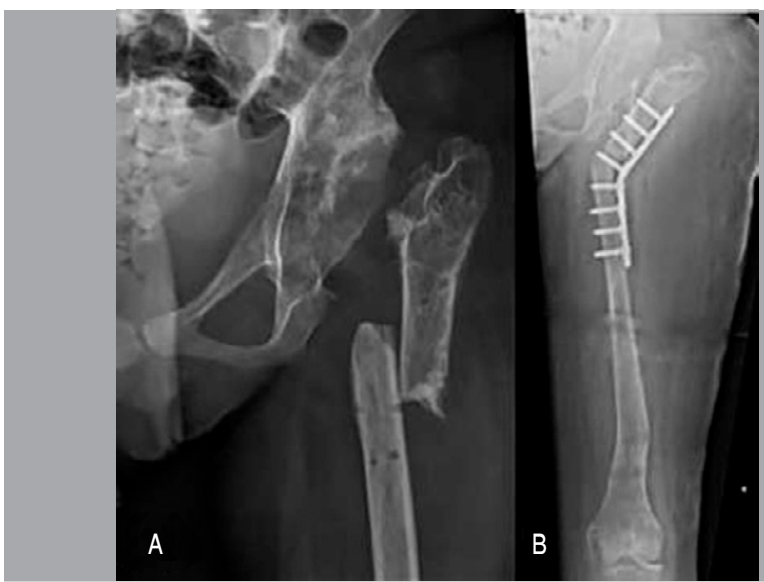

Figure 3. Illustration of complication after the treatment and its solution A: figure of a complication with bone fracture at the site of proximal osteotomy in a 15 -year-old patient; B: aspect after the pelvic support was rebuilt and fixed with low contact plate. The plate was previously angled to maintain the support achieved before the fracture.

\section{DISCUSSION}

A hip in a vicious, unstable, and painful position, due to great destruction of the joint, as in the cases presented in this report, causes several gait and posture disorders due to pelvic instability. Shortening and associated vicious contractures are also considered. As a result, the individual tries to rebalance in order to compensate some insufficiency by making an exaggerated contralateral inclination of the trunk in the support phase of gait, associated with hyperlordosis of the lumbar spine and increased pelvic anteversion, if there is contracture in hip flexion. This process leads to muscle fatigue and great overload of the spine, which hampers the treatment of low back pain. Thus, the proximal pelvic support osteotomy aims to improve the mechanical conditions of gait and posture., ${ }^{1,9}$ The objective is to medialize the center of gravity as close as possible to its original position, thus reducing the mechanical lever arm and relieving the abductors. ${ }^{10}$ The osteotomy also allows the correction of hip flexion contracture, if any, which did not occur in the cases studied. For some time there was discussion whether the greatest effect of osteotomy would be by supporting the pelvis itself or by improving the strength of the gluteus medius. These questions are based on the observation that in some younger patients the angle was remodeled by age growth, but pelvic stability was maintained. Furthermore, magnetic resonance imaging showed that a significant improvement in muscle mass of the gluteus medius occurred after surgery. ${ }^{9}$ This muscle mass enhancement is due to the repositioning further away from the trochanter, with increased lever arm for abductors. ${ }^{1}$ Currently, both effects are considered significant and the surgery is recommended after 12 years of age, when the ability of spontaneous osteotomy rectification is lower. The median age in our series was 15 years, and the youngest patient was 11 years old.

Currently, with the use of total hip prosthesis, these patients are treated by arthroplasty. One of critics on pelvic support osteotomy is that it can hinder the performance of an arthroplasty in the future, since the intramedullary canal of the femur will be deformed and both residual defects of the cortex and adhesions may occur. ${ }^{10,11}$ Another possible complication would be pain caused by the impact of the osteotomy angle on the ischium, ${ }^{12}$ but this has not been reported in the literature.

Pain was not assessed because it was not reported in any case, perhaps due to low age. The technique is complex, involves significant risks, but we had no irreversible complications. All patients in the study presented complications during the proposed treatment, $90.9 \%$ of which required new procedures under anesthesia, such as manipulation of the knee joint and treatment of infectious processes around the fixation wires. Patients and family members should be well-guided about the length of treatment, high rate of complications and realistic expectations. An unusual complication, because we did not find reference to it in the literature, were two fractures in the proximal osteotomy region. Usually the local repair bone presents good quality when using the llizarov apparatus, in any condition. One possibility to avoid this complication would be prophylactic fixation of proximal osteotomy with a plate at the same surgical time as the external fixation apparatus was removed. One of the problems that we could not fully address was the shortening, whose correction was partial in some cases, due to severe limitation of knee movement. Thus, further lengthening is one possibility to complete the correction.

\section{CONCLUSION}

The double femoral osteotomy analyzed here provided good results considering the severity of the sequela and the lack of another therapeutic option. There were no major complications associated with the treatment, but there was incomplete correction of the shortening

AUTHORS' CONTRIBUTIONS: Each author contributed individually and significantly to the development of this article. MDSP: data acquisition and analysis, illustrations and drafting of the manuscript; PHB: surgeon responsible for cases, examination of patients, analysis of results and critical revision of the text; JBV: writing and final revision of the text, critical revision and final approval of the version for submission. 


\section{REFERENCES}

1. Samchukov ML, Cherkashin AM, Birch JG. Pelvic support osteotomy and limb reconstruction for septic destruction of the hip. Operat Tech Orthop. 2013;23(3):158-66.

2. Pafilas $D$, Nayagam $S$. The pelvic support osteotomy: indications and preoperative planning. Strategies Trauma Limb Reconstr. 2008;3(2):83-92.

3. Gaenslen FJ. The Schanz subtrochanteric osteotomy for irreducible dislocations of the hip. J Bone Joint Surg. 1935;17(1):76-87.

4. Milch H. The "Pelvic support" osteotomy: 1941. Clin Orthop Relat Res. 1989;(249):4-11.

5. Reynders-Frederix P, Reynders-Frederix C, Wajid M. Pelvic support osteotomy: salvage procedure in chronically dislocated hips case report: technical note on the on-lay bone positioning of a lengthening nail and review of the literature. Open Orthop J. 2016;10:232-40.

6. Paley D. Problems, obstacles and complications of limb Lengthening by Ilizarov technique. Clin Orthop Rel Res. 1990;(250):81-104.

7. Paley D. Hip joint considerations: pelvic support osteotomy. In: Paley D. Principles of deformity correction. New York: Springer; 2002. p. 689-94.
8. Marimuthu K1, Joshi N, Sharma CS, Bhargava R, Meena DS, Bansiwal RC, et al. Ilizarov hip reconstruction in skeletally mature young patients with chronic unstable hip joints. Arch Orthop Trauma Surg. 2011;131(12):1631-7.

9. Inan M, Alkan A, Harma A, Ertem K. Evaluation of the gluteus medius muscle after a pelvic support osteotomy to treat congenital dislocation of the hip. J Bone Joint Surg. 2005;87A(10):2246-52.

10. Mahran MA, Elgebeily MA, Ghaly NA, Thakeb MF, Hefny HM. Pelvic support osteotomy by llizarov's concept: is it a valuable option in managing neglected hip problems in adolescents and young adults? Strategies in Trauma Limb Reconstr. 2011;6(1):13-20.

11. Sonohata M, Kitajima M, Kawano S, Tanak R, Mawatari M. Total hip arthroplasty with femoral subtrochanteric osteotomy after Schanz osteotomy. J Orthop Sci. 2016;21(4):469-74

12. Safram M, Ryu J. Ischiofemoral impingement of the hip: a novel approach to treatment. Knee Surg Sports Traumatol Arthrosc. 2014;22(4):781-5.

13. Bukva B, Vrgo G, Rakovac I, Du i S, Sindik J, oklo M, et al. Complications in leg lengthening using an llizarov external fixator and intramedullary alignment in children: comparative study during a fourteen-year period. Injury. 2015;46(6):S48-51. 